Original paper

\title{
Social Innovation Hackathon for Driving Innovation in Disaster Risk Reduction (DRR)
}

\author{
Ambika Dabral ${ }^{1 *}$, Sukhreet Bajwa ${ }^{1}$, Satsuki Shioyama ${ }^{2}$, Ranit Chatterjee ${ }^{1,2}$ and Rajib \\ Shaw $^{1,3}$
}

Received: 31/12/2020 / Accepted: 15/06/2021 / Published online: 28/09/2021

\begin{abstract}
Time and again, disasters bring forth various challenges concerning risk communication, disaster-resilient infrastructure, last-mile delivery, disaster reporting, etc. These challenges often highlight the existing gap between research and academicians, and the policymakers and practitioners. Secondly, it brings forth the lack of adequate collaboration among experts and practitioners of different fields. Most of these challenges require innovative and low-cost solutions catering to local and contextualized problems, and calls for a multi- and transdisciplinary approach and collaboration.
\end{abstract}

With this vision, amidst the current pandemic of COVID-19, Resilience Innovation Knowledge Academy (RIKA) India, Indo-Japan Laboratory (Keio University, Japan) and four partnering universities have launched the Social Innovation Online Hackathon (SIOH) 2020. SIOH aims to provide a unique virtual platform to student innovators and mission-driven entrepreneurs from different fields like architecture, engineering, disaster management, etc., to collaborate and develop innovative solutions for tackling the pandemic and future disasters.

The paper aims to introduce SIOH and its four-step process as a tool of multi-disciplinary collaboration to promote innovation for Disaster Risk Reduction (DRR). Besides the critical outcomes of the $\mathrm{SIOH}$, the paper seeks to flag some indirect positive impacts of such an exercise. Among others, these include, firstly, the introduction of the field of DRR to academicians and practitioners of other sectors, thereby paving the way for its mainstreaming in other sectors. Secondly, such an exercise involving young students envisages to invoke a spirit of inquiry and innovation, which is crucial for bringing social change. Thirdly, it

\footnotetext{
${ }^{1}$ Resilience Innovation Knowledge Academy (RIKA) India Pvt. Ltd.

* Corresponding author Email: dabral.ambika@gmail.com

${ }^{2}$ Kyoto University, Japan

${ }^{3}$ Keio University, Japan
} 
highlights the critical role of proper sectoral mentorship in handholding the young innovators in their journey of building resilient societies.

Keywords: Innovation, disaster risk reduction, resilient, youth, entrepreneurs

\section{INTRODUCTION}

\section{Brief background and problem/gap}

While disasters bring considerable destruction, they also provide an opportunity to learn from the process and recover stronger. Finding innovative approaches to risk reduction and management are among such opportunities. The recent development and implementation of effective evidence-based approaches call for the application of innovation in science and technology, as well as in the social domain. Despite the recognized importance of scientific and evidence-based policy-making in DRR, the policy-making keeps operating in silos without integrating the practices and knowledge of the DRR (Albris et al., 2020). The Sendai Framework for Disaster Risk Reduction (SFDRR) advocates for an increase in investment to support innovation. One of the foremost gaps identified in the implementation of priorities of SFDRR pertains to the limitation of the knowledge management system, which integrates knowledge on DRR and engages the domain's experts in policy-making (Rahman and Fang, 2019). Hackathons are one of the most effective platforms for devising intuitive solutions in a limited time frame. In this aspect, the paper explores the case study of the Social Innovation Online Hackathon (SIOH) as a means and process of channelizing the creativity and energy of young students, towards innovative and entrepreneurial prospects. The SIOH uses digital technology to bring together students from different regions and academic skills and ushers in the use of technology to create solutions to various development challenges. The lack of supportive policies and initiatives limits the use of innovation, and science, and technology in DRR (Izumi et al., 2019b). An increased co-production of knowledge, resources with practitioners and researchers, helps develop innovations, and $\mathrm{SIOH}$ is one of the platforms to bring together the stakeholders in DRR. This also helps in enhanced communication between the stakeholders and in bridging the gap between national and local initiatives and resources (ibid). The social sciences play an important role in new thinking on risk, vulnerability, poverty, and the human roles in DRR (ibid). The inter-disciplinary concepts foster innovation in resilience and facilitate feeding local information into DRR policy-making.

\section{Methods}

The paper uses a case study approach to better understand the social innovation hackathon in DRR and sustainable development. The Indo-Japan Laboratory (IJL), Keio University 
(Japan), and Resilience Innovation Knowledge Academy (RIKA) India in collaboration with the four coveted Indian universities, namely, Indian Institute of Technology (IIT) Roorkee, IIT Hyderabad, National Institute of Technology (NIT) Durgapur, and Visvesvaraya National Institute of Technology (VNIT) Nagpur jointly organized the Social Innovation Online Hackathon (SIOH) 2020. The close monitoring and evaluation of the SIOH helped in developing the current case study. The team undertook four rounds of assessments over two and a half months using different monitoring and evaluation tools to study the experience of involved innovators, mentors, the SIOH process, and its impacts. These tools included scoring rubrics, descriptive assessment, and online questionnaire-based assessment using Google forms. The developed questionnaire included both closed and open-ended questions targeting different phases of the SIOH. The assessments using the scoring rubrics were temporal and helped in comparing the understanding, learning, impacts, and overall experience of the innovators at the onset and completion of the SIOH. The paper captures the process of the $\mathrm{SIOH}$, and some of these key changes, for highlighting the challenges faced and learning for future improvements in conducting and nurturing social innovation in DRR and sustainable development.

\section{INNOVATION AND INCUBATION}

Incubation is the process in which a nascent idea is nurtured and developed as an entrepreneurial start-up. Incubators are like launchpads for ideas to get progressed as implementable projects (Bajwa et al., 2021). The concept of the incubator originated in the early 1950s in the United States. The term incubator is derived from the root term, which means nurturing; incubators develop small companies in a protected environment (Rodrigues and Franco, 2019). Incubators provide support to budding entrepreneurs in the early start and development of their ideas. They help grow the idea through mentorship and association with industry networks and provide support in forming new partners, creating business models, integrating marketing techniques, and financial support. They provide financial support through seed funding, easing the access to market funds through loans or venture capitalists.

As per (Tidd et al., 2005), there are four types of innovations; i) product innovation; ii) process innovation, which involves alternative ways of creating products; iii) position innovation, which involves ways of introducing products in the market, and; iv) paradigm innovation, which targets shifting of perception. The global policy frameworks highlight the increasing role of science and technology, the private sector, and research to achieve their targets. Priority 3 of the Sendai Framework refers to the importance of private investment, private cooperation, and business resilience. The Sustainable Development Goals (SDGs) talk about the need for investment in innovation, partnership, and sustainability. The Private Sector Alliance for Disaster Resilient Societies (ARISE) Initiative of UNDRR endeavors to increase the private sector's participation in DRR. In India, the Prime Minister's 10-point agenda 
highlights the importance of research, universities, and the role of the private sector's cooperation with the government in DRR.

In this aspect, social innovation is a process whereby the resultant solution or idea aims to address social problems. We can understand the domain of social problems from the envisaged goals and targets of the global frameworks of SDGs and SFDRR. Through their 17 goals, SDGs highlight the key issues of poverty, health, education, infrastructure, environment, etc., which can be taken up as challenges for innovation. Public-private partnership is one of the main platforms for visualizing and achieving social innovation. Social innovation may or may not lead to social entrepreneurship. When social innovation becomes the key focus of the incubation, those incubators may help drive the idea towards entrepreneurial ventures through training. As per (Murray et al., 2010), there are six stages of social innovation, namely: i) Prompts- which highlight problems and inspirations with a need for a solution; ii) Proposalswhich include idea generation process; iii) Prototypes-which focus on idea testing; iv) Sustaining- for integration of idea daily life along with steady revenue source; v) Scaling- for expanding the idea to different sectors through both increases in demand and supply, and; vi) Systemic change- which leads to a macroscopic change in the overall business, economy, or in the identified sector.

\section{Key challenges}

The main challenges in the sector of incubation for social innovation are the limited option of growth and the reliability of funding sources (Murray et al., 2010). Since the business perspective may be limited in social innovation, it attracts fewer private investors. Further, the grant donors are more biased towards programs and projects than investing in incubators for social innovation (ibid).

\section{INNOVATION HACKATHON}

The term hackathon is derived from two words: hacking and marathon (Komssi et al., 2015). This refers to an intense and continuous period of programming to crowdsource solutions for technological and social problems. Hackathons allow small groups to work on a specific challenge to derive solutions. Hackathons are popular in the technology world and require innovative thinking to develop a working model or prototype within a defined duration. Further, hackathons are social events that provide opportunities to meet new people and ideate with people from different disciplines and backgrounds. A hackathon begins with idea generation and team building as the first step. The group members are organized based on their skill set, and interest in the specific idea. Thereafter, within a specific time duration, the groups develop a working model to demonstrate solutions to the specific problem. Post-hackathon, the plausible solutions are often carried forward through sponsorships. Hackathons enable a 
bottom-up and collaborative approach to develop innovative ideas (ibid). Organizations conduct hackathons for their internal staff and teams to promote innovation and ideation. Such hackathons are called internal hackathons. The external hackathons involve a wide range of stakeholders from the local community, industry, academia, or government. External hackathons often lead to the generation of new start-ups.

\begin{tabular}{|c|c|c|}
\hline $\begin{array}{l}6 \text { months before } \\
\text { the event }\end{array}$ & $\begin{array}{l}4 \text { months before } \\
\text { the event }\end{array}$ & $\begin{array}{l}2-3 \text { months before } \\
\text { the event }\end{array}$ \\
\hline Decide your theme & Decide the format & . Establish the code of conduct \\
\hline Identify your target & Decide the timing and date & . Pick judges, speakers, mentors \\
\hline \multirow[t]{5}{*}{ audience } & . Launch the website & Decide prizes \\
\hline & . Lock down a venue & Promote \\
\hline & Identify sponsors & \\
\hline & Set rules & \\
\hline & Decide the giveaways & \\
\hline $\begin{array}{l}1 \text { month to } 1 \text { week } \\
\text { before the event }\end{array}$ & Day Zero & Post D-Day \\
\hline \multirow[t]{3}{*}{ Get ready for the event } & Put it all together & Keep promises to all \\
\hline & on D-Day & stakeholders \\
\hline & & . Follow up post the event \\
\hline
\end{tabular}

Figure 1: Basic format of the hackathon

Source: (HackerEarth, n.d.)

Social innovation hackathon goes beyond technological solutions and looks for ideas in new processes or new products that positively impact society. Social innovation hackathon builds solutions in the field of development. While commercial innovation aims at increasing profit margins, social innovation seeks to reduce disparity and strives to generate social capital through intervention (McKercher, 2017). The COVID-19 crises have witnessed increased social innovation events to counter the pandemic (Gegenhuber, 2020). The social innovation hackathon conducted in Germany (ibid) helped mobilize civil society towards innovative solutions and get funding from the government for the winning ideas. Social innovation hackathons help in community engagement and specifically provide a platform for youth to engage in problem-solving. Hackathons conducted with young innovators help to focus on local issues and enhance engagement with the local community. For environmental and climate change issues, the youth are already leading the change through their voices in the field of policy-making (ABC News, 2019). Hackathons conducted in universities offer opportunities for networking with industry partners, thus broadening the scope of employment options for the youth. 
Despite the various objectives innovation hackathons fulfill, such as facilitating collaborations to ignite new ideas, they do not always lead to lasting innovations and market successes (Sastry and Penn, 2015). One of the key reasons for this is that innovation is inherently an iterative process of problem identification and solving, and often, the hackathons with the "winner-take-all" approach discourage the innovators from cherishing and learning from this iterative journey of innovation (ibid). Moreover, the closed ecosystem made available to the innovators during a hackathon tend to limit them from engaging with, understanding, and meaningfully undertaking ground/market studies (ibid). The concept of open innovations can address this limitation. Open innovation in the corporate world allows innovators' engagement with external stakeholders for enhancing the understanding and quality of the outcomes (Flores et al., 2018)

\section{INNOVATIONS AND INCUBATION IN DRR}

\section{Factors triggering innovation in DRR}

The world is witnessing substantial increase in the magnitude and frequency of disasters. The ever-increasing population, greater exposure \& vulnerability meeting the climate-induced hazards result in intense and frequent disasters (Thomas and Lopez, 2015). Further, the nature of the hazards is evolving and giving rise to new, emerging and complex risks. The changing nature, intensity, and frequency of these disasters have caused a fundamental change and innovation in the existing approaches, products, and services to manage disasters and disaster risks. Additionally, underlying complex factors like rapid and unplanned urbanization, poverty, and environmental degradation, require more than conventional solutions and DRR measures (Izumi et al., 2019a). Besides the changing landscape of climate and disaster risks, there is a significant development in science and technology over the years. The policy landscape in disaster risk management has also evolved significantly right from the Yokohama Strategy and Plan of Action for a Safer World, International Decade for Natural Disaster Reduction (IDNDR), to the adoption of the Sendai Framework for Disaster Risk Reduction (2015-30). The emerging landscapes have triggered the evolution of research and innovation in the field (Shaw, 2020).

The year 2015 witnessed global leaders resolve to strive to build a safer and sustainable world resilient to climate and disaster risks. This led to the adoption of various global frameworks and agreements, including the Sendai Framework, the 2030 Agenda for Sustainable Development, the Paris Climate Agreement, and the New Urban Agenda. The synchronous adoption of these frameworks and agendas provides and calls for multistakeholder and multi-sectoral collaborations along with the promotion of science and technology (Murray et al., 2017). The practical implementation of these frameworks and agendas depends on the presence of a facilitating ecosystem that supports increased use of science, technology, innovation, knowledge-sharing, and capacity development (UN, 2017). 
The Sendai Framework emphasizes investing in innovation for a better understanding of disaster risks and driving solutions towards disaster risk management (UN, 2015). This call for innovation in disaster risk management is not new. Earlier, the Hyogo Framework for Action 2005-15 had emphasized the "use of knowledge, innovation, and education for building the culture of safety and resilience at all levels" (UN, 2007).

Apart from these, a critical factor resulting in the effective implementation of innovations in different aspects of DRR is advancing scientific research and technologies in various related fields. For example, while the idea of earthquake early warning systems was conceptualized in 1868 by J.D.Cooper, the same could be implemented and tested much later after advancements in digital seismic instrumentations and digital communication technologies (Dabral et al., 2021).

\section{Current status}

Like any other field, the innovations in DRR are not limited to products but are inclusive of process, approach, frameworks, and concepts, among others (Izumi et al., 2019b). Innovation in DRR can be hazard-specific, or thematic, or concerning different phases of disaster management. As a multi- and inter-disciplinary field, DRR provides a great opportunity for innovation in its diverse dimensions, which are inclusive of natural, ecological, socio-cultural, economic, psycho-social aspects. Besides, there are various existing innovations targeting different phases of disaster management, such as prevention \& mitigation, preparedness \& capacity building, response \& relief, and reconstruction, rehabilitation \& recovery. Many innovations in DRR such as early warning systems, construction practices, and disasterresilient practices are found to be very effective (ibid). Further, community-based DRR and risk management top the most effective innovations for DRR (Izumi et al. 2019b).

(Izumi et al. 2019a) recorded 30 innovative DRR products and approaches found effective for mitigating disaster risks. These include 14 products and 16 approaches. Some of these products are technological products such as GIS and remote sensing, drones, Doppler radar, earthquake early warning, etc. These have been useful in undertaking evidence-based interpretation, decision making, and raising timely alerts and warning for different hazards. Some products aimed at strengthening the infrastructural resilience include disaster-resilient materials, school cum cyclone shelter, concrete, and steel.

In contrast, other products include studies and survey exercises such as seismic microzonation and electricity resistant surveys. The key innovative approaches identified in (ibid) cater to different aspects of DRR such as hazard mapping, assessments, and terminologies enhancing the understanding of risk and supporting risk communication. Approaches such as Community-Based Disaster Risk Reduction (CBDRR), traditional practices, and evacuation behaviors and indigenous DDR technologies underscore the importance of community as a key stakeholder of DRR. Other innovative approaches such as Hyogo Framework for Action, the National Platform for Disaster Risk Reduction, and transnational initiatives on resilient cities have effectively laid down guiding and collaborative institutional mechanisms for DRR. 
These innovative products and services were assessed on 6 critical parameters, including cost-effectiveness, impact on reducing deaths \& number of affected persons, reduction in economic loss, level of application/penetration, environmentally friendly, and role in bringing behavioral change. A survey of academicians, NGOs, government, and private actors helped in understanding the effectiveness of these innovative products and services (Izumi et al., 2019a). The survey found that both products and approaches are effective innovations that enhance the existing DRR efforts towards addressing newer challenges (ibid).

\section{Existing gaps}

The newer challenges today in global society have highlighted the limitation of existing science and innovation systems and underscored the need for stronger support and promotion of science and innovation interface (OECD, 2004). For this, policies, funds, resources and stakeholders strengthening the science and innovation interface are required. The multi-sectoral and all-of-society approaches imbibed in the processes of DRR need to be reflected while undertaking the research and innovations of DRR. Besides these, the transboundary nature of climate and disaster risks such as the ongoing COVID-19 pandemic, cyclones, floods, and ecosystem degradation require a better understanding of the prevailing risks across borders, supported by cross-border knowledge sharing and collaboration, and innovation. However, platforms providing opportunities to diverse, multi- \& inter-disciplinary, and cross-border innovators to come together to brainstorm and collaborate for DRR are not yet really popular.

The common perception of innovation being synonymous with technology is flawed. Innovation is inherently a human-centered process that includes inquiring, analysis, testing, and learning from unsuccessful attempts. While these can yield technological solutions but that may not always be the case (Callegaron 2017). (Izumi et al. 2019a) states that innovations may not always be high-technology products but can also be soft-measures like approaches and frameworks.

\section{CASE STUDY OF SOCIAL INNOVATION ONLINE HACKATHON (SIOH) 2020}

Amidst the uncertainties and disruption brought by the COVID-19 pandemic to the normal socio-economic functioning of the global society, the SIOH 2020 facilitated continuity of collaborative ideation and creation by young innovators. Because of the physical restrictions posed by the pandemic, the SIOH envisaged providing a virtual platform to innovators, academicians and field practitioners, and experts from diverse fields for co-creating solutions for social good and wellbeing (IJL and RIKA India, 2020). The key objectives of the SIOH include finding unique \& innovative solutions for tackling impediments for sustainable development and DRR, co-creating local solutions for increasing societal resilience, promoting innovation and entrepreneurship among youth and young professionals, and encouraging the use of science and technology for social innovation. 


\section{Themes and stakeholders of SIOH}

The themes of SIOH targeted at six of the SDGs and envisaged to address some of the related socio-economic and ecological challenges which got aggravated during the COVID-19 pandemic. The six themes pertained to zero hunger (SDG 2), health and well-being (SDG 3), gender (SDG 5), clean water and sanitation (SDG 6), safe cities and communities (SDG 11), climate action (SDG 13). The forty-six students from the five participating universities were divided into six thematic groups for the SIOH based on the initial ideas proposed by them. The composition of the groups further ensured academic diversity through participants belonging to thirteen different academic disciplines such as disaster management, computer science, architecture, urban studies, and policy studies. Each group had students belonging to two countries, different universities and academic levels, such as graduation, post-graduation, and doctoral.

\section{SIOH 2020: Process}

$\mathrm{SIOH}$, which lasted for close to two and a half months, comprised of four stages to provide a systematic and guided experience to the young innovators on their journey of co-creating products and services for social good. These four stages are:

i. Ideation stage: This was the inception of the $\mathrm{SIOH}$, and the stage allowed participating groups to virtually connect, brainstorm, discuss, and streamline their ideas.

ii. Maturation stage: The stage focused on consolidating and strengthening the group ideas by exploring and attempting to address the perceived implementation challenges.

iii. Tangible prototype development stage: This included putting the respective group ideas to test using different tools like online and field surveys of potential end-users, beneficiaries, and other stakeholders. The surveys helped the groups in identifying the gaps in the innovation and improving it. The stage also included the development of UI-UX-based interface designs by some groups to showcase their piloting strategies.

iv. Marketing strategy stage: During this stage, groups developed and refined their business model and strategies. The groups assessed their ideas for market feasibility and potential to generate revenue, while being commercially sustainable over time.

\section{Mentoring and monitoring}

Throughout the entire process of $\mathrm{SIOH}$, the six groups were closely guided, supported, and monitored by six professors and twenty-one thematic and cross-cutting mentors who were academicians, DRR practitioners, subject experts, and members of private sectors. Two to three thematic mentors assigned to each of the six groups provided theme-specific guidance and handholding across different stages of SIOH. These included mentoring on aspects of both hard and soft skills such as originality \& practicality of the ideas, relevance of ideas to themes, scalability-adaptability-sustainability of the innovation, and strategies for effective brainstorming, problem-solving, presentation \& communication skills, and time management. 
The cross-cutting mentors were common for all groups. They provided overarching guidance to the groups on aspects of present gaps and challenges in innovation, practical applicability of innovations, understanding markets and end-users. Overall, thirty-five mentoring sessions of over fifty-two plus hours were conducted across different stages of the SIOH.

SIOH included four monitoring sessions spread across different stages of the SIOH to evaluate and assess the progress of each of the groups. Under these sessions, each group presented their ideas and progress made to a team of mentors and professors who evaluated the groups and provided feedback for improvement.

\section{SIOH 2020: Impact}

The $\mathrm{SIOH}$ resulted in the consolidation of thirty-eight initial ideas to six final ideas. Three groups pitched their ideas to a larger audience comprising government authorities, private sector actors, potential investors, etc. Overall, the six innovations proposed by the groups have successfully identified the ground challenges in respective themes. The innovations broadly addressed a host of issues including supporting the livelihood of informally-operating street vendors during the current pandemic, providing safe queue management systems at COVID19 testing and other health facilities, and facilitating water-efficient urban farming methods. They also focused on connecting local communities, with a view to help overcome the challenges of social isolation and other issues posed by an urban lifestyle, enabling plastic waste segregation at source in urban communities, et cetera.

Apart from these tangible innovations (products, services, platforms), $\mathrm{SIOH}$ made some intangible impacts on the participating groups, recorded through the four rounds of assessments (table 1). Assessments 1 and assessment 2 targeted the groups to understand their functioning, performance and temporal changes therein during the ideation (July 14, 2020) and maturation stages (August 18, 2020) through peer-based and self-assessment, respectively. The assessments used the tools like scoring rubrics and descriptive assessments. These assessments allowed the innovators to reflect on their as well as other groups' performance. Assessment 3 and assessment 4 were targeted at evaluating the process and impact of the $\mathrm{SIOH}$, respectively. These assessments capture the individual learning, growth of the innovators, their experience, and feedback for improving the SIOH.

Assessment 1 and 2 evaluated the groups and individuals on parameters like comprehension, accuracy of information used, logical thinking, presentation material, attitude, and time management. The comparative results of peer assessment of group 1 are represented in figure 2. Responses A, B, C, N respectively refer to the most suitable, next suitable, less suitable, and non-applicable options under each of the six parameters. Figure 2 illustrates the positive change (in percentage) in the members of group 1 for almost all parameters. There is a remarkable improvement on the parameter of attitude (an increase from $2 \%$ to $15 \%$ for the most suitable option A). Similarly, time management of the group also improved significantly. 
Table 1: Four rounds of assessments under SIOH

\begin{tabular}{|c|l|l|l|}
\hline Assessment & \multicolumn{1}{|c|}{ Aim of assessment } & \multicolumn{1}{c|}{ Respondents } & \multicolumn{1}{c|}{ Tools used } \\
\hline Assessment1 & $\begin{array}{l}\text { To evaluate groups' functioning } \\
\text { and performance through peer- } \\
\text { assessment during ideation \& } \\
\text { maturation phase }\end{array}$ & $\begin{array}{l}\text { Student } \\
\text { innovators (all } \\
\text { groups) }\end{array}$ & $\begin{array}{l}\text { Scoring rubrics, } \\
\text { descriptive assessment }\end{array}$ \\
\hline Assessment 2 & $\begin{array}{l}\text { To evaluate groups' functioning } \\
\text { and performance through self- } \\
\text { assessment during ideation \& } \\
\text { maturation phase }\end{array}$ & $\begin{array}{l}\text { Student } \\
\text { innovators } \\
\text { (respective group } \\
\text { members) }\end{array}$ & $\begin{array}{l}\text { Scoring rubrics, } \\
\text { descriptive assessment }\end{array}$ \\
\hline Assessment 3 & $\begin{array}{l}\text { To evaluate the process of } \\
\text { innovation }\end{array}$ & $\begin{array}{l}\text { Student } \\
\text { innovators }\end{array}$ & $\begin{array}{l}\text { Questionnaire (both } \\
\text { closed and open-ended } \\
\text { questions) }\end{array}$ \\
\hline Assessment 4 & $\begin{array}{l}\text { To evaluate the overall impact of } \\
\text { the SIOH }\end{array}$ & $\begin{array}{l}\text { Student } \\
\text { innovators }\end{array}$ & $\begin{array}{l}\text { Questionnaire (both } \\
\text { closed and open-ended } \\
\text { questions) }\end{array}$ \\
\hline
\end{tabular}

Source: Authors
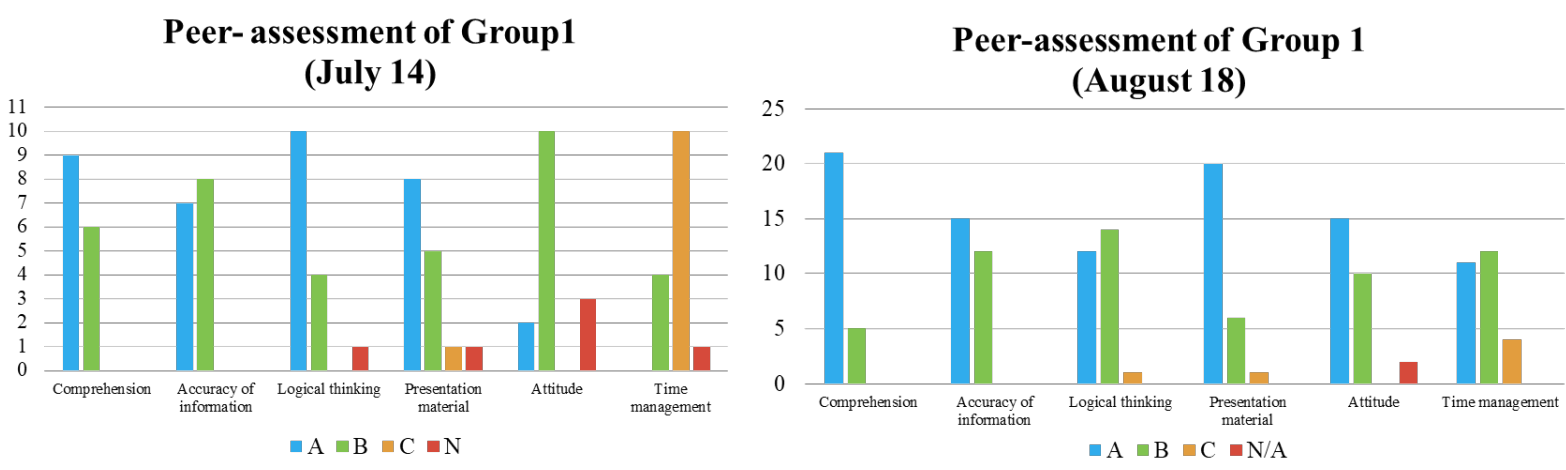

Figure 2: Comparative peer-assessments of group 1

Source: Authors

Similarly, based on the results of assessment 3, figure 3 illustrates the consolidated comparative changes in the effective use of presentation material by the six groups. It reflects that five out of six groups showed improvement in the effective use of presentation materials during the maturation stage compared to the ideation stage. In contrast, one group scored almost the same in both stages. These groups gained substantial skills to use graphs, charts, figures, info-graphics, audio-visual aids, etc. to illustrate better and put forward the identified problems and the proposed ideas. 
Score of Presentation Material

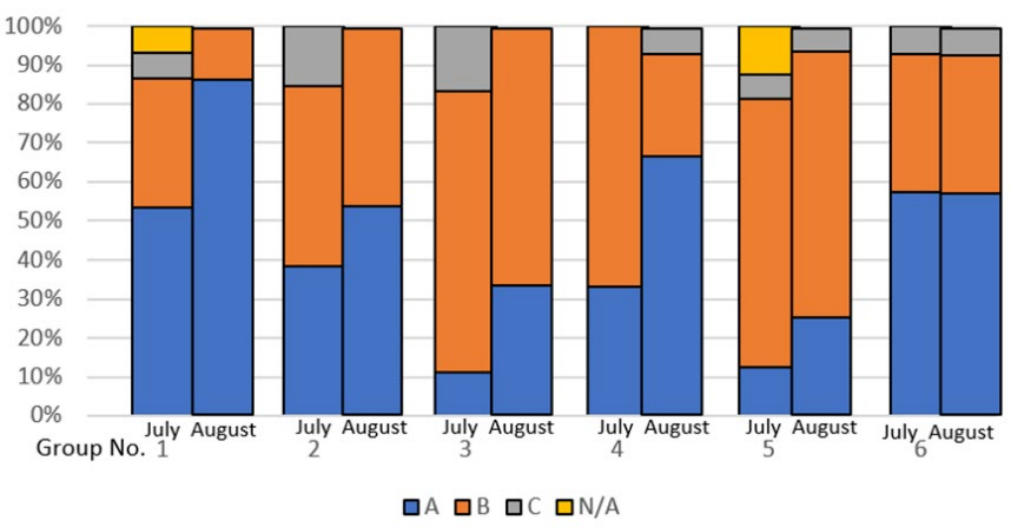

Figure 3: Consolidated comparative assessment of groups on the aspect of presentation material

Source: Authors

According to the result of assessment $4,62 \%$ of the group members had worked towards improving the existing products/services in overcoming prevailing gaps and bottlenecks. In comparison, $25 \%$ had worked towards developing a completely novel innovation. Similarly, during the $\mathrm{SIOH}, 63 \%$ of the respondents proposed technology-driven solutions, while $31 \%$ proposed solutions that used technology but were not technology-driven.

Regarding the mentorship sessions, around $63 \%$ of respondents found both types of mentorship helpful, while $26 \%$ found thematic sessions (and $11 \%$ cross-cutting) more helpful. $84 \%$ of the respondents found thematic mentors provided precise guidance to the groups.

The SIOH process allowed the groups opportunities for networking and mutual learning. Around $25 \%$ of the respondents shared and discussed the problems and ideas with other members and built inter-university networking, while around $31 \%$ of the respondents interacted with members of other teams but belonging to their own universities. Members of different groups proactively took part in the team meeting and different mentoring sessions. Around $64 \%$ of the respondents helped their group progress by articulating ideas, facilitating problemsolving, and fostering discussions.

Based on these assessments, some of the intangible impacts of SIOH included developing a better understanding of the groups on aspects of entrepreneurship, DRR, and acquisition of new skills, among others. Figure 4 illustrates that $50 \%$ and $47 \%$ of the group members who participated in the assessment strongly agree and agree, respectively, on the role of SIOH in enhancing their understanding of different aspects of entrepreneurship. 58\% of the respondents agreed that SIOH helped them better understand different aspects of DRR. 


\section{SIOH helped in better understanding of entrepreneurship}

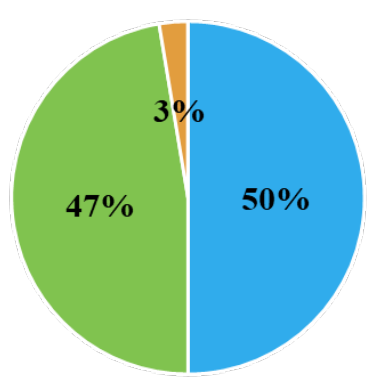

- Strongly agree

- Agree

Neutral

- Disagree

- Strongly disagree

\section{SIOH helped in better understanding aspects of disaster risk reduction}

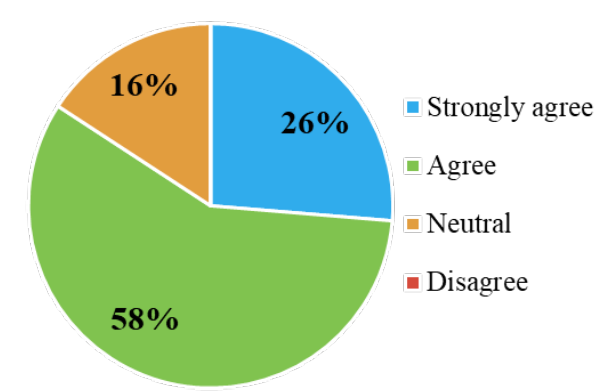

Figure 4: Impact of SIOH in enhancing understanding of entrepreneurship and DRR

Source: Authors

It is evident that the $\mathrm{SIOH}$ process has resulted in the acquisition of varied skills such as problem-solving, entrepreneurship, application development, time management, interpersonal $\&$ leadership, et cetera. Figure 5 represents the new skills acquired by the students and respective percentages of students.

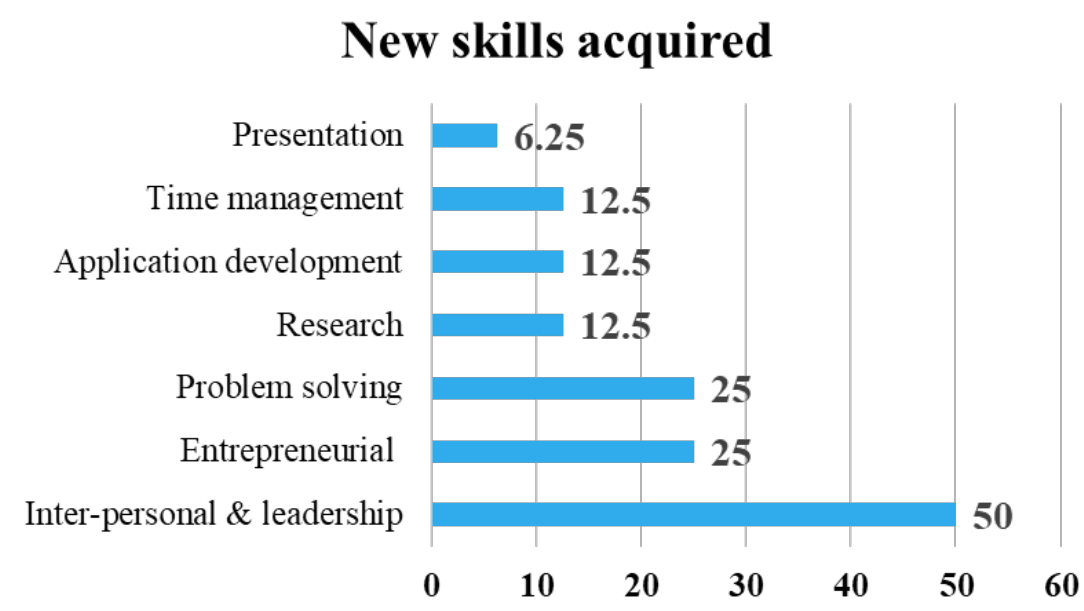

Figure 5: Acquisition of new skills by innovators during $\mathrm{SIOH}$

Source: Authors

The survey showed that $84 \%$ of the respondents participated in a hackathon for the first time, and around $66 \%$ were interested in participating in similar hackathons in the future. This highlights that the SIOH was able to invoke the spirit of inquiry and innovation in the youth. Furthermore, $58 \%$ of the respondents were also interested in further exploring and pursuing DRR. 


\section{DISCUSSION}

SIOH envisioned developing innovative products, services, and approaches and exploring and testing the four-step process of multi-disciplinary collaboration to promote innovation for DRR. From this perspective, it was necessary to evaluate not only the performance and success of the innovators in SIOH but also to capture the intangible learning and opportunities such a platform can provide to the young innovators. Thus, apart from the rigorous evaluation of the groups on different aspects discussed earlier, four assessments closely studied the process of $\mathrm{SIOH}$. These included peer-based and self-assessment of different innovator groups. This is not a common feature of any conventional hackathons. The self-assessment allowed the innovators to evaluate their own group's performance. The peer-based assessments allowed them evaluate the performance of other groups. This supported cross-learning and helped the students to better understand the innovation process both as innovators and as peer-evaluators. By undertaking temporal assessments using scoring rubrics, the change in soft skills such as communication, time management, teamwork, leadership skills was effectively gauged. The assessment was useful in understanding the immense potential such platforms have in supporting interdisciplinary collaboration and cross-learning for driving social innovation. The findings of the assessment would aid in enhancing such platforms in the future.

$\mathrm{SIOH}$ provided a unique opportunity for innovators to work in diverse groups that were cross-country, inter-university, and inter-disciplinary. This helped the groups foster crosssectoral mutual learning, acquire new skills, and co-create through a holistic lens of related fields. Unlike the conventional hackathon, which often uses a short-duration 'pressure cooker' environment for the participants to innovate, SIOH was conducted over a longer duration of over two and a half months, where even many first-time innovators participated and co-created. (Hulsheger et al., 2009) as cited in (Uusi-Kakkuri et al., 2016) suggests that at the team level, leaders can play a crucial role in promoting innovation by effectively conveying motivating targets, providing valuable and encouraging feedback that is supportive of innovations. In the case of the $\mathrm{SIOH}$, the group leaders, whom their respective groups mutually proposed, played this important role. They ensured that group members stayed motivated and worked together as a team. This was crucial, as the group members belonged to different countries, universities, disciplines, and academic levels. In addition to this, the groups found the concept of thematic and cross-cutting mentoring sessions to be very effective in hand holding them throughout the duration of the SIOH. The sessions kept the groups motivated and nurtured the ecosystem for deliberations with the experts and field practitioners. They also helped the groups in streamlining their ideas and making them more actionable.

At the same time, because of the virtual nature of the $\mathrm{SIOH}$, some groups experienced the challenges of working in different time zones and ensuring effective intra-group communication and coordination. This is often not the case when an individual works with a known group-member. However, the SIOH aimed to help the innovators overcome these softskill-related limitations of coordination and communication, and to better prepare them for real-world working environment. 
As recorded by (Sastry and Penn, 2015), the closed ecosystem, provided to the innovators during a conventional hackathon, limits their potential engagement with and understanding of the end-users and the market. SIOH, during its 'market strategy stage' envisaged overcoming this bottleneck by encouraging its innovators to use different tools to study and engage with market players and end-users. (Hulsheger et al., 2009) as cited in (Uusi-Kakkuri et al., 2016) highlights that engaging and communicating with external stakeholders enhances creativity. Almost all the groups undertook surveys to engage with the end-user and beneficiaries of their products/ services (in case of product innovation) or with existing stakeholders \& authorities (in case of process innovation). The online survey for better studying the market, end-users, and beneficiaries helped the groups in creating contextualized solutions that were best suited and more acceptable to the end-users. Some of the key stakeholders engaged by different groups included government authorities, non-governmental organizations, private organizations, street vendors, health workers, local communities, etc. In due consideration of the prevailing pandemic, the stakeholder engagements were both physical and virtual, depending on specific groups' local restrictions and requirements. This was possible because of the long duration of the $\mathrm{SIOH}$, which allowed adequate time to groups to engage with stakeholders and improvise on the innovations to make them sustainable and effective. Besides, through cross-cutting mentorship sessions, the innovators got the opportunity to engage with experts and practitioners from diverse fields and academic disciplines.

The experience of SIOH further underscores the prevailing perception of innovation being technology and/or technology-dependent. There is a need to break this perception to encourage young minds and practitioners from non-technical and social fields for co-creation and innovation. However, such a change in perception should be duly supported by providing adequate financial and other support to ideas and innovations that are not technology-driven or dependent but are effective in bringing the envisaged changes in respective fields.

SIOH strived to overcome the earlier identified gap by (Sastry and Penn, 2015) about hackathons often following the 'winner-take-all' approach. Apart from the three finalized groups of $\mathrm{SIOH}$, the other three participating groups got the opportunity to address the gaps and further improve their innovation if they wish to. The interested groups were further supported under the 'Seeds of Innovation Program' of RIKA India. This becomes crucial for motivating young minds and practitioners and building a culture of co-creation and innovation.

\section{THE WAY FORWARD}

From the context of four types of innovations (product, process, position, and paradigm) discussed earlier, SIOH brought to the front that it may not always be possible to categorize the innovations as only one of the four types of innovations. Different groups of SIOH worked on innovative ideas belonging to more than one of these four types. For example, some of the groups working on product innovation, undertook market research and measures to assess how to best introduce their product in the market, which relates to position innovation. The group 
working on the theme of Safe Cities and Communities, through their product targeted at mitigating social isolation in urban communities, envisaged changing perception of end-users, thus relating indirectly to paradigm innovation. Thus, possibly, there is a need to retrospectively study innovations from a not-so-rigid typology and leave the scope for inclusion of ideas that fall under a hybrid type.

(Chanal, 2012) emphasizes on two methods for knowledge production, namely engagement with field practitioners and endorsing an interdisciplinary approach. A single discipline, alone, cannot adequately understand and address the nuances of existing and emerging societal and environmental challenges. The key to knowledge creation and social innovation lies in interdisciplinarity (ibid). The experience of SIOH demonstrates that by adding more DRR specific themes in similar hackathons in the future, young minds from different disciplines and fields can engage in driving local and cost-effective innovation in DRR and other societal issues. The hackathon can have more thematic sessions for sensitizing the diverse teams on core aspects of DRR and other fields with lack of/inadequate innovations.

Innovation drives and supports sustainable socio-economic needs and growth of society (OECD, 2004). The support and role of partnering universities in the SIOH showcase the possibilities whereby academic institutions can act as thematic incubators for their students belonging to diverse disciplines and academic levels. Similar recommendations are reflected in (Chanal, 2012) reflects similar recommendations and calls for universities to enhance their traditional roles of undertaking research by also playing the role of "innovation-promoting knowledge hubs." (Unger et al., 2017) discusses the concept of the knowledge triangle prevailing between research, education and innovation. The interlinkages and interaction possible within the knowledge triangle should be further explored and leveraged by the academic and research institutions, private sector and industry, government and other stakeholders.

The cooperation and partnership of academia and industry can nurture social innovation (Chanal, 2012). On similar lines, (Oksanen, 2013) recognizes knowledge, collaboration, and motivation as key factors that support innovation. The case of SIOH where academic institutions and private bodies collaborated for driving innovations in DRR and sustainable development, should be widely promoted and replicated with necessary tweaking. These can be very helpful for addressing and finding solutions to local problems of an area duly identified by the local administration and government bodies, or local NGOs. Various measures/models for strengthening the linkage of knowledge triangle between research, education and innovation include, amidst others, "academic start-ups and incubators; open science/innovative platforms; public-private partnership models; geographical and sectoral mobility of innovators; promotion of industry-focused programs and skills" (Unger et al., 2017). SIOH considered some of these crucial aspects. As it was the first such initiative by the organizers, SIOH was open to participation to only five partner universities as a pilot model for promoting social innovation. To further achieve the envisaged goals, SIOH or other similar innovative platforms should be open to a larger number of universities to reach out to more young innovators. Besides this, SIOH provided a virtual geographical and sectoral intermingling of the young innovators and mentors during the ongoing pandemic. 
Apart from the initiative of SIOH, RIKA India has collaborated with some of the academic institutions to promote and establish thematic incubators (Bajwa et al., 2021). These themes include "women leadership in DRR and climate change; smart city and climate change adaptation; urban sustainability and design" (ibid). Such mechanisms need further exploration and endorsement for driving and fostering social innovation. There is a need to institutionalize such existing platforms that nurture young minds and practitioners to collaborate and co-create for social change. (Oksanen, 2013) characterizes an innovative space as one which nurtures and supports collaboration \& communication; is flexible enough for modifications to facilitate diverse activities and experiments; capable of providing a socio-technical intellectual ecosystem; attracts and supports the flow of innovative ideas; and reflects the key values of openness, sustainability and collaboration.

\section{REFERENCES}

ABC News. (2019). 'How dare you':? This is Greta Thunberg's passionate cry for climate action. Retrieved December 29, 2020 from https://www.youtube.com/watch?v=N94eP2jKQWw

Albris, K., Lauta, K. C. \& Raju, E. (2020). Disaster Knowledge Gaps: Exploring the Interface Between Science and Policy for Disaster Risk Reduction in Europe. International Journal of Disaster Risk Science, 11(1): 1-12. Retrieved December 31, 2020 from https://link.springer.com/article/10.1007/s13753-020-00250-5

Bajwa S, Dabral. A., Chatterjee, R. \& Shaw, R. (2021). Co-designing Knowledge Innovation through Thematic Incubators for Disaster Risk Reduction and Sustainable Development. Sustainability, 13(4). From https://www.mdpi.com/2071-1050/13/4/2044

Callegaro, A. (2017). Why innovation and technology aren't the same. UNHCR. Retrieved December 29, 2020 from https://www.unhcr.org/innovation/innovation-technology-arent -the-same/\#: : text=Innovation $\% 20$ is $\% 20 \mathrm{a} \% 20$ human $\% 2$ Dcentered,innovation $\% 20$ doesn t $\% 20$ equal $\% 20$ technology.

Chanal, V. (2012). Building knowledge for innovation management: The experience of Umanlab research team. VINE, 42(3/4). Retrieved May 15, 2021 from https:/www.emerald.com/insight/content/doi/10.1108/03055721211267512/full/html

Dabral A, Sasaki. K., Nizhamudong, Y., Chatterjee, R. \& Shaw, R. (2021). Innovation in earthquake early warning system: A case study of EQ Guard. In Emerging Technologies for Disaster Resilience. Springer. Retrieved December 30, 2020 from https://link.springer.com/chapter/10.1007/978-981-16-0360-0_3

Flores M, Golob, M., Maklin, D., Herrera, M., Tucci, C., Al-Ashaab, A, ... Pineda, K. F.. (2018). How Can Hackathons Accelerate Corporate Innovation? In I. Moon, G. M. Lee, J. Park, D. Kiritsis, \& G. Cieminski, Advances in Production Management Systems. Production Management for Data-Driven, Intelligent, Collaborative, and Sustainable Manufacturing. IFIP Advances in Information and Communication Technology. APMS 2018 (Vol. 535, pp. 167-175). Springer. Retrieved December 27, 2020 from https://link.springer.com/chapter/10.1007\%2F978-3-319-99704-9_21\#citeas

Gegenhuber, T. (2020). Countering Coronavirus With Open Social Innovation. Retrieved December 29, 2020 from Standford Social Innovation Review: https://ssir.org/articles/entry/countering_coronavirus_with_open_social_innovation 
Hackerearth. (n.d.). The complete guide to organizing a successful hackathon. Retrieved December 27, 2020 from Hackerearth: https://www.hackerearth.com/communityhackathons/resources/e-books/guide-to-organize-hackathon/

IJL, Keio University, RIKA India. (2020). Social Innovation Online Hackathon. Retrieved December 27, 2020 from https://rikaindia.com/wp-content/uploads/2020/08/Final-reportSIOH.pdf

Izumi, T., Shaw, R., Ishiwatari, M., Djalante, R. \& Komino, T. (2019). 30 Innovation for DRR. Retrieved December 29, 2020 from https://apru.org/wp-content/uploads/2019/03/30Innovations-for-Disaster-Risk-Reduction final.pdf

Izumi, T., Shaw, R., Djalante, R., Ishiwatari, M. \& Komino, T. (2019). Disaster risk reduction and innovations. Progress in Disaster Science, 2. Retrieved November 28, 2020 from htt ps://www.sciencedirect.com/science/article/pii/S259006171930033X

Komssi, M., Pichlis, D., Raatikainen, M., Kindström, K. \& Järvinen, J. (2015). Whatare Hack athons for? IEEE Software, 32(5), 60-67. Retrieved December 30, 2020 from https://ieee xplore.ieee.org/document/6809711

McKercher, K. A. (2017). Understanding the differences between commercial and social innovation | Part 1 of 2. Retrieved December 29, 2020 from https://medium.com/@kamc kercher/understanding-the-differences-between-commercial-and-social-innovation-part-1 -of-2-c4ed576e31da\#: : :text=Commercial $\% 20$ innovation $\% 20$ rarely $\% 20$ focuses $\% 20$ on,th ose $\% 20$ who $\% 20$ need $\% 20$ support $\% 20$ most.

Murray, R., Caulier-Grice, J. \& Mulgan, G. (2010). The Open Book of Social Innovation. NESTA, The Young Foundation. Retrieved December 29, 2020 from https://media.nesta.org.uk/documents/the open_book_of_social_innovation.pdf

Murray, V. , Maini, R., Clarke, L. \& Eltinay, N. (2017). Coherence between the Sendai Framework, the SDGs, the Climate Agreement, New Urban Agenda and World Humanitarian Summit, and the role of science in their implementation. Retrieved December 28, 2020 from https://www.preventionweb.net/publications/view/53049

OECD. (2004). Science and Innovation Policy: Key challenges and opportunities. Retrieved December 30, 2020 from http://www.oecd.org/science/inno/23706075.pdf

Oksanen, K., \& Ståhle, P. (2013). Physical environment as a source for innovation: investigating the attributes of innovative space. Journal of Knowledge Management, 17(6): 815-827. Retrieved $\quad$ May $20, \quad 2021$ from https://www.emerald.com/insight/content/doi/10.1108/JKM-04-2013-0136/full/html

Rahman, A. \& Fang. C. (2019). Appraisal of gaps and challenges in Sendai Framework for Disaster Risk Reduction priority 1 through the lens of science, technology and innovation. Progress in Disaster Science, 1. Retrieved December 31, 2020 from https://www.sciencedirect.com/science/article/pii/S2590061719300067

Rodrigues, M., \& Franco, M. (2019). The Corporate Sustainability Strategy in Organizations: A Systematic Review and Future Directions. Sustainability, 11(22). Retrieved December 28, 2020 from_https://www.mdpi.com/2071-1050/11/22/6214

Sastry A, \& Penn, K. (2015). Why Hackathons Are Bad for Innovation. Retrieved December 30, 2020 from Fast Company: https://www.fastcompany.com/3054023/why-hackathonsare-bad-for-innovation 
Shaw, R. (2020). Thirty Years of Science, Technology, and Academia in Disaster Risk Reduction and Emerging Responsibilities. International Journal of Disaster Risk Reduction, 414-425. Retrieved December 28, 2020 from https://link.springer.com/article/10.1007/s13753-020-00264-Z

Thomas, V. \& López, R. (2015). Global Increase in Climate-Related Disasters: ADB Economics Working Paper Series. Asian Development Bank. Retrieved December 28, 2020 from https://www.adb.org/sites/default/files/publication/176899/ewp-466.pdf

Tidd, J \& B essant, J. (2005). Managing Innovation: Integrating Technological, Market and Organizational Changes (3rd ed.). John Wiley \& Sons, Ltd.

United Nation. (2017). New Urban Agenda. Retrieved December 28, 2020 from https:/unhabitat.org/sites/default/files/2019/05/nua-english.pdf

United Nations Office for Disaster Risk Reduction. (2007). Hyogo Framework for Action. Retrieved December 28, 2020 from https:/www.undrr.org/publication/hyogo-frameworkaction-2005-2015-building-resilience-nations-and-communities-disasters

United Nations Office for Disaster Risk Reduction. (2015). Sendai Framework for Disaster Risk Reduction (2015-30). Retrieved December 28, 2020 from https://www.preventionweb.net/files/43291 sendaiframeworkfordrren.pdf

Unger, M., \& Polt, W. (2017). The Knowledge Triangle between Research, Education and Innovation- A Conceptual Discussion. Foresight and STI Governance. Retrieved May 16, 2021 from https://cyberleninka.ru/article/n/the-knowledge-triangle-between-researcheducation-and-innovation-a-conceptual-discussion/viewer

Uusi-Kakkuri, P., Brandt, T., \& Kultalahti, S. (2016). Transformational leadership in leading young innovators- a subordinate's perspective. European Journal of Innovation Management, 19(4). Retrieved May 20, 2021 from https://www.emerald.com/insight/content/doi/10.1108/EJM-12-2014-0118/full/html 